University of Nebraska - Lincoln

DigitalCommons@University of Nebraska - Lincoln

To Improve the Academy

Professional and Organizational Development Network in Higher Education

1998

Planning Multicultural Audits in Higher Education

Mark A. Chesler

Follow this and additional works at: https://digitalcommons.unl.edu/podimproveacad

Part of the Higher Education Administration Commons

Chesler, Mark A., "Planning Multicultural Audits in Higher Education" (1998). To Improve the Academy. 400.

https://digitalcommons.unl.edu/podimproveacad/400

This Article is brought to you for free and open access by the Professional and Organizational Development Network in Higher Education at DigitalCommons@University of Nebraska - Lincoln. It has been accepted for inclusion in To Improve the Academy by an authorized administrator of DigitalCommons@University of Nebraska - Lincoln. 
Chesler, M. A. (1998). Planning multicultural audits in higher education. In M. Kaplan (Ed.), To Improve the Academy, Vol. 17 (pp. 171-202). Stillwater, OK: New Forums Press and the Professional and Organizational Development Network in Higher Education. Key Words: assessment, change strategies, evaluation methods, faculty attitudes, organizational climate.

\section{Planning Multicultural Audits in Higher Education*}

\section{Mark A. Chesler}

University of Michigan

Colleges and universities are struggling with issues of diversity and multiculturalism-in classrooms, social interactions, staff relations, admissions and hiring processes, and overall campus climate. As part of organizational change efforts, many institutions are calling on faculty development offices to help plan, staff, and implement cultural audits or assessments. This article suggests tested procedures for designing and carrying out such audits, with examples of specific data-gathering techniques (and in some cases evidence) from various institutions. Cultural audits will be most successful, accurate, and useful when these procedures are considered carefully and built into the audit design at the beginning.

Substantial recent research and commentary make it clear that discrimination on many bases-race, gender, sexual orientation, class, religion, etc. - continues to exist in our nation's colleges and univer-

\footnotetext{
* Many of the ideas in this article have come from collaborative work with Beth Reed and James Crowfoot, critical commentary from Matt Kaplan and Lisa Mets, and wisdom from audit teams with whom I have worked at several colleges and universities. The provision of colleagueship and a fellowship as a Multicultural Faculty Associate of the University of Michigan's Center for Research on Leaming and Teaching greatly facilitated the preparation of this article.
} 
sities. While we can learn many general lessons from this research, change efforts require us to particularize and specify the conditions of discrimination, and the hopes for diversity and multiculturalism, in each distinct organizational setting. Indeed, Smith (1989) suggests that local assessments or audits are a critical initial strategy in local change efforts, strategic plans to reduce discrimination in both its overt and covert forms, and the creation of more multicultural environments.

In particular, faculty development staffs can play a central role in designing, gathering, and using information to improve the content and process of classroom instruction and local unit/organizational climates. Their particular expertise in instructional design and evaluation is a vital resource in assessment and improvement efforts. But these talents also must be tuned to the wider organizational setting within which classrooms exist, instructors teach, curricula are framed, and much of student and faculty life takes place.

\section{Background and Strategic Plan Development}

A multicultural audit is like any other institutional research or data-gathering effort; it requires thoughtful planning, specific expertise, careful data collection and analysis, and clear reports and recommendations. But an audit is not simply an effort to gather and analyze data; it is an intervention into the organization's life. The desire to create an audit usually results from concern about the current state of campus affairs and/or a parallel desire to improve organizational functioning. Moreover, any effort to gather data with regard to issues of multiculturalism - whether race, gender, age, class, sexual orientation, religion, ability status-necessarily draws attention to their presence and role in organizational life. Given the level of conflict and controversy surrounding these issues and the resistance to information that may challenge certain groups' expectations and traditional privileges or advantages, we can expect the audit to be a focal point for dialogue and debate. If the audit is successful in raising consciousness, it will probably expose underlying conflicts as well. The clearly political (and probably conflictual) nature of a multicultural audit must be acknowledged and attended to throughout the stages of design and implementation. 
Because of these background factors, it is important to build the audit into a larger strategic plan for making changes that promote diversity and multiculturalism. Otherwise, a completed audit may end up being a waste of time and energy, sitting and gathering dust. Or it may become the flashpoint for controversy that detracts from the core struggle over discrimination and change. As Wunsch \& Chattergy (1991) note, assessing the campus cultural climate is only the first step in programming and implementing change around issues of diversity and multiculturalism. Later steps involve developing a vision, plan, and strategies for a more multicultural and socially just classroom/campus climate (Chesler, 1994; Cox, 1993; Jackson \& Hardiman, 1994). As we take the first steps, it is vital to plan carefully for successive steps as well.

\section{Objective: An Assessment/Audit}

Initial and recurrent assessments help raise the organization's level of awareness of problems, may take the burden of "awarenessraising" or "consciousness development" off the shoulders of aggrieved constituencies and place it in the center of the organization's planning efforts, and can help inform and direct the goals and tactics of a change effort. Since much of the discrimination that exists in colleges and universities is invisible to or overlooked by members of the dominant groups (generally white and male students, faculty, and staff), the audit also may serve the function of making covert processes overt and educating everyone regarding the existence of problematic situations - situations that may dramatically contradict the organization's rhetorical mission and ideals.

The development of a clear mission and leadership commitment for the multicultural audit, and more broadly for multicultural changes, are essential prerequisites. In addition, the audit should be planned in ways that quite deliberately lead into implementation efforts and further activities, namely the creation of recommendations and an action plan for change. Thus, part of the job of the audit is to educate and prepare key personnel, including the group doing the audit, for the change process that it is part of and that will follow (or accompany) it. 
The goal must be to create an audit that is technically sound and substantively meaningful, but that does not take an endless amount of time and energy to create. While traditional academic research concerns about reliability and validity may not be primary, they are still relevant, and the work must have high credibility and relevance for the issues at hand. This approach is consistent with the tradition of action-research or participatory-action-research, in which a priority on organizational improvement and empowering organizational members for change has at least an equal priority with advances in knowledge (Brown \& Tandon, 1983; Gaventa, 1993; Peters \& Robinson, 1984; Stoeker \& Bonacich, 1970). Thus, the audit should be done in a way that: (1) utilizes internal organizational leadership; (2) creates high participation and substantial trust in the process and findings; (3) develops insights and ideas about the feasibility of various change efforts; (4) maintains links with varied constituencies so that a supportive environment exists for subsequent change activities; (5) empowers constituencies to act for change; and (6) builds continuing capacity for such assessment (and reassessment) into the school's personnel and operations.

\section{Steps in Conducting an Audit}

1. Create a cultural audit or assessment "team." When the unit conducting the audit is internal to the organization, great care must be taken in its selection and preparation. The development of a multicultural team does not merely mean recruiting people who are truly interested in this work, and people from diverse social identity groups and constituencies; it also means creating a working environment and interpersonal relationships that mirror the nature of a multicultural activity. Miller (1988) discusses a number of issues involved in creating a multicultural team, including attention to norms, concepts of team play, membership, leadership, and a forthright focus on internal racism and sexism. Unless these issues are attended to successfully, the team will struggle endlessly with its own processes of racism, sexism, etc., with dysfunctional interpersonal and group dynamics, and with the organization's pre-existing structures and cultures. There are numerous examples of well-intentioned and 
competent audit teams foundering on exactly these reefs. The process of creating a multicultural team will take time and energy, and special meetings or retreats dedicated to this goal. Nor is this a one-time concern; team development issues and racist/sexist "baggage" will arise throughout the life of the audit, and these internal process concerns should be addressed regularly. If the audit is contracted out to an external agency that agency, too, must be selected and monitored as to its multicultural construction and operation.

In addition to the process of team creation, the multicultural audit team should prepare itself for the audit by:

- Investigating the nature of discrimination and diversity or multiculturalism in the U.S. society and in higher education in general, and in this particular type of university or college (e.g., secular or religious, public or private, research-oriented or liberal arts, graduate or undergraduate, etc.);

- Exploring and sharing their own ideologies, perceptions, and experiences regarding life at their college;

- Sharing views of classroom and out-of-classroom experiences;

- Getting acquainted with comparable audits, both procedurally and substantively.

The breadth of these preparatory steps emphasizes the importance of a wide range of skills in the team and calls for the inclusion of faculty development personnel, research specialists, multicultural advocates, and colleagues and co-workers who could be part of a larger group of advisors to the audit and the eventual change effort.

2. Prepare the school for open assessment and discussion of issues and problems of equity-inequity, discrimination, cultural diversity, and multiculturalism. This broader educational and political process must be undertaken by the school's leadership cadre and should include:

- Public clarification of the school's diversity mission and vision, how this relates to other goals and missions, and the role of the audit in this mission; 
- Orientation of key constituencies and powerful figures in the school to the audit process;

- Evidence of support or commitment for the audit by the President, Deans and Directors, and other legitimate authorities.

It is essential that faculty members be centrally involved in this process, both in their roles as teachers and as organizational citizens, as should faculty developers, experts in understanding and working with the needs and skills of faculty members. Other key constituencies include students and staff/administrators, and perhaps alumni. Above all, senior leadership support and commitment is crucial, because the audit team must be able to trust that organizational leaders (or whoever sponsors the audit) are sincerely interested in accurate information, no matter how positive or negative, and are committed to advancing diversity and multiculturalism and combatting discrimination. Of course, at the outset no one can say what actions senior leaders or anyone else may take or commission on the basis of audit results, but if the team does not believe leadership is committed to using the data for multicultural organizational improvement, they will lack energy and commitment for what may appear to be "a waste of time." At times the commitment of senior leaders will have to be "tested" and demonstrated-in word and deed.

There are also situations where the initiative for an audit may be generated from "below," from low-power or aggrieved stakeholders in the organization. This may be the case when groups that have raised concerns have been ignored or have been told that their concerns are insubstantial or unrepresentative or their complaints only "anecdotal." Their interest in an audit may be to document and make public the nature and extent of their negative experiences in the organization. Quite naturally, then, support and commitment from senior leadership may not be forthcoming; or at least it may not be present initially. Hopefully, it can be solicited and garnered later in the process. If not, the audit is likely to become a hotly debated resource in a public political struggle, once again potentially distracting energy from the core goal of reducing discrimination and approaching multiculturalism. The issue here is not to avoid such struggle and conflict, but to keep the focus on the right issues. 
3. Design the audit itself. There are several sub-steps involved in the design phase: (1) deciding what issues will be explored; (2) deciding from whom (or from what constituencies or identity groups or interest groups) or where information will be sought; and (3) deciding what information-gathering strategies will be used.

The first sub-step can be facilitated by creating a list of the key issues that are of concern. The following list will differ according to the type of school involved, the issues that are locally present or potent, and any specific incidents or grievances that have surfaced. More generally, however, a coherent audit can address the following organizational parameters.

- Multiple issues or foci of information sought -culture(s) of the school and its constituent units -representation of diverse peoples at various salary levels and in various roles -instructional content and processes (curriculum and pedagogy) -peer relations, both formal and informal (among students, among faculty, etc.)

-cross-status relations (between faculty and staff, between students and faculty, etc.)

-quality of services delivered (if service-related sector or department) -member satisfaction (including students) -management and leadership practices -human resource and personnel policies -character of research being conducted -incidents or public examples of racism, sexism, etc. -interest in or feasibility of particular changes regarding diversity and multiculturalism -nature and location of resistance to change

One example of a conceptual "map" of organizational discrimination, and thus "what to look for or at" for useful information, is contained in Figure 1 (Chesler \& Crowfoot, 1997, p.2). Other maps can be created to target the more specific or multiple domains of diversity or discrimination being explored. 


\section{FIGURE 1}

\section{Discrimination in Higher Educational Organizations*}

MISSION (Purposes)

Explicit attention to goal of social justice/equity lacking

No recognition of plural goals/interests

Commitment to the status quo of the institution and social order

Creativity and inventiveness assumed to be limited to whites/males

Multicultural/antiracist/antisexist/anti-homophobic metoric not tied to action strategies

CULTURE (Dominant belief systems and rules of the game)

Monocultural norms for success promulgated

Traditional norms for "appropriate" behavior/dress/expression

Alternative cultures not explicitly recognized or promoted and marginalized if acknowledged

Diversity and excellence seen as competitive or contradictory and played off against one another

Rituals/symbols reflect white, male, Eurocentric dominance or exclusivity

No explicit rewards for innovations

Diversity a problem, not a source of richness

POWER SYSTEM (By whom and how decisions are made)

Senior power holders are white and male, with female staff or subordinates

Informal hierarchy of the "white male club"

Subunits not required to deal with racism or sexism proactively

Office of Minority Affairs (sic) exists, but not as a central part of university structure or operations

Protests by students of color seen as trivial or disruptive and dealt with via repression or short-term concessions

STRUCTURE-SOCIAL (How people relate)

Faculty/staff/student social networks generally exclude people of color and gay/lesbian people

Social relations among students of different races not seen as a university-wide concern, and especially not as a faculty or academic concern

"Climate" issues not dealt with explicitly

No coherent or proactive policy of response to racial and sexual harassment

TECHNOLOGY-CURRICULUM AND PEDAGOGY (Means to accomplish core tasks)

Curriculum does not include/address different cultures' contributions to knowledge

Curriculum does not explicitly address issues of racism/sexism/homophobiain discliplines, campus, or community

Traditional instructional pedagogies are unaltered 
FIGURE 1, Continued..

Lack of opportunities for (re)training faculty to work with diverse group of students Traditional patterns of counseling, advising, and mentoring are relied upon

RESOURCES (Materials, funds, people, facilities)

Funds not available to support/maintain multicultural innovations

Active recruitment of students/faculty/staff of color nonexistent or unsuccessful

Post-recruitment support for students/faculty of color and women minimal

"Vital agendas" compete (often successfully) for scarce resources

Technical staff not skilled in multicultural change

BOUNDARY SYSTEMS (Relations with external environments)

Lack of vigorous outreach to diverse communities

Racist/sexist/homophobic/classist community settings and incidents not addressed

Alumni of color not seen/treated as vital

Sole "mportant" public constituencies are white and male and affluent

Traditional relations with traditional "majority" suppliers, recruiters, and placements

*Chesler \& Crowfoot, 1997, p. 2

The second design sub-step is to decide from whom or about whom (or about what) information will be sought. For instance:

- Multiple sources of data

-students

-faculty

-administrators or higher level executives

-board members

-staff

-parent, community members, or representatives of the

public at large

-alumni(ae)

-personnel and other records

-curricula

-documents reflecting policies and programs

-minutes of meetings or events

-notes from workshops on teaching

-materials collected by faculty developers (classroom

videotapes and evaluations) 
Assuming that part of the audit's focus is on the larger organization outside the classroom, it is especially important that people of color and women (and members of other obviously or potentially aggrieved groups) be included as data sources, for their experience often is highly informative about the covert nature of organizational discrimination. Moreover, it is important to gather data from white people as well as people of color, and men as well as women, because the contrasts or similarities between their perceptions of the environment will help to clarify the way even apparently fair and just organizations may create different working and learning conditions for people of different backgrounds and social locations. If the audit focus is narrower, perhaps on the improvement of teaching, it may make sense to limit data-gathering to the experiences and needs of students (of varied backgrounds) and faculty members (of varied backgrounds) and to omit some of these other data sources.

The third sub-step involves deciding what information-gathering strategies will be used. For instance, many audits include a mix of:

-questionnaires

-personal interviews

-small group interviews (focus groups)

-observations at key organizational sites and of key processes

-written materials and documents

-observations and evaluations of classroom teaching -reports from special events, "hearings," or town meetings -meetings discussing preliminary reports of the audit -ethnographies of student, faculty, and staff life

Good and practical but brief discussions of the comparative advantages and disadvantages of some of these data-gathering methods can be found in Deadham (1980), Lockwood \& Luthans (1980), and Thomas (1984). The choice of instruments will depend on the audit focus and purpose (e.g., interviews will do better at uncovering covert discrimination than will questionnaires) as well as local logistics and resources (e.g., questionaires are much more cost effective than faceto-face interviews). 
Instruments and specific questions exist for almost all these issues/foci, information sources, and data-gathering strategies. And various higher educational organizations have used these strategies and provided examples in their self-studies or reports of campus or unit audits. For instance, the University of Michigan (1992), Indiana University (1991), the University of Wisconsin-Madison (1987), and many others, report statistical profiles reflecting the existence and representation of students, faculty, and staff of color. Questionnaires and surveys have been used by Michigan State University (1991) to assess faculty and academic staff members' views of diversity issues, by Pennsylvania State University (1992) to assess faculty and student views regarding gay and lesbian issues, by Massachusetts Institute of Technology (1986) to assess minority students' views of the quality of campus life, by the University of Michigan (1994) and Princeton (1993) to assess various student groups' views, by Wellesley College (1989) to assess the experiences of students and faculty of color and white students and faculty, and by the School of Dentistry at the University of Michigan (1995) to assess student, staff, faculty and patient views of the School's cultural climate. The University of California at Berkeley (1991), the School of Public Health at the University of Michigan (1990), and Chesler, Wilson \& Malani (1993) used focus group interviews to gather the experiences and outlooks of students of color and white students, and George Mason University (1991) used both group and individual interviews in a similar venture. Individual interviews also were used by the University of California system (with faculty and students-1987), Pennsylvania State University (with gay and lesbian students - 1992), and LeMoyne College (with department heads-1991). Green (1989) has developed a series of checklists with which to investigate institutional policies, and many colleges and universities produced reports of their student, faculty, and staff demographic profiles. Finally, and creatively, several colleges used data collected at "open forums" or public meetings where issues were discussed or survey data reported (Wellesley, 1989; Massachusetts Institute of Technology, 1986). At the State University of New York (1989) a series of "bias-related" activities were investigated and reported in detail. In several cases, the collegiate self-reports warn readers that their sampling procedures were deliberately "not repre- 
sentative" of the population of their institutions, even though the results were informative, trustworthy on their face, and useful in writing and planning recommendations for change. Specific examples of potential audit items exist in and can be appropriated from some of the sources cited above, and any of their examples can be modified to fit different organizational goals and circumstances (see the Appendix to this paper). Additional campus audits focused on diversity are reviewed briefly in Levitan \& Wolf (1994).

Decisions on these three sub-steps are not independent of one another, and choices of information sought will influence from whom they will be gathered and the strategies to gather them. Thus, specific design decisions have to be made that link the information-gathering strategies to the foci of information sought to the sources of such information. Moreover, the creation of a time-line for completing various activities (although such time-lines are notoriously underestimated) and appropriate divisions of labor (and/or the creation of sub-committees) among audit team members (or external resource persons) will be useful. The following worksheet items, adapted and edited from the audit conducted by the Multicultural Initiatives committee of the Cultural Audit Committee of the University of Michigan's School of Dentistry (1995), provide an example of this integrative design activity.

- What do we want to achieve-what information do we want (foci)?

\section{Assess attitudes}

Gather stories about experiences

Assess behaviors

Assess barriers to change

Assess policies and their impact

- How do we want to achieve it - how do we get this information?

Committee discussions

Questionnaires to people in the school

Focus group conversations/interviews

Analysis of the curriculum

Analysis of statistical data on school membership 
- From whom (where) do we want to get this information?

Students

Staff

Faculty

Alumni/ae

Patients

School records

- When do we want each of these pieces delivered?

In most instances, plans for data collection and analysis will have to be approved by an institutional human subjects review board. Such boards may be unaccustomed to dealing with audits of their own organization, as contrasted with reviewing proposals to conduct research in external environments. They may be particularly discomforted by questions probing delicate race, gender, and sexual orientation issues, or by the possibility of exposing "negative" information about the college or unit. This is one more example of the unique properties (and sometimes difficulties) distinguishing a multicultural audit from most other institutional review procedures or research efforts.

4. Set the stage for the "audit." Links must be established with various constituencies and committees of the school (Staff Advisory Committee, Executive Committee, Faculty Senate, Trustees, Student Governments) to inform them of the audit, to prepare them to participate, and to gain their assistance and legitimation. It also is vital to gain the cooperation of varied interest groups, including groups of students and faculty of color, women's caucuses, etc. (especially if there are small numbers of these groups on campus). This is an important step in promoting and ensuring a high response and participation rate, and a high-response rate is itself an important aspect of the audit's eventual credibility and utility.

Groups that feel disadvantaged or oppressed by the organization are not likely to trust the audit process any more than they trust the organization in general; and they may not be willing to respond to this effort unless reassured of their safety and the audit's utility and relevance for their lives. Likewise, people and groups (or units) opposed to the multicultural agenda itself may be unwilling to respond 
to a multicultural audit unless they, too, are reassured that their voices will truly be heard.

5. Gather the information. Based upon decisions made in step 3 (above) data can now be gathered. Unless the audit team is rather large, other faculty and staff members, graduate student assistants and interns, computer experts, research departments or classes, and other technically skilled personnel may be called upon to assist in the effort to collect and analyze data. There is considerable debate currently as to whether the most "honest" data results when the people gathering data are of the same social backgrounds as those they gather data from (e.g., Should only people of color interview students and faculty of color? Should only women staff members interview women staff members?). This question is unresolved at present and arguments on both sides are powerful and convincing; audit teams need to be aware of and to consider this issue carefully and perhaps try several different answers to see how they work.

The specific steps involved in gathering the data include:

- Selecting a sample of people and places from which to gather information

- Monitoring the information-gathering process as it occurs

- Altering the design as required by early responses

Some collegiate self-reports have used quite large samples and others have used relatively small data bases. For example, in the Michigan State University report (1991), 775 faculty and academic staff members returned questionnaires; at Wellesley College (1989), all students and faculty of color and approximately $30 \%$ of the white students and faculty were provided with questionnaires; and at the University of Michigan (1994), all 4500 incoming students in the undergraduate class of 1994 received surveys and several follow-up surveys, and interviews ensued. On the other hand, at LeMoyne College (1991, p.44), 64 people "intimately involved with and concerned about diversity" were interviewed; at George Mason University (1991), 150 people participated in 47 personal interviews and 17 group interviews; and at the university of California at Berkeley (1991), 230 students participated in 55 focus groups - some of which were racially/ethni- 
cally heterogeneous and others racially/ethnically homogeneous. If a large number of people are to be included in a questionnaire survey or series of interviews, more assistance will be required. Moreover, if extensive individual or group interviews are planned, special care must be taken to train interviewers in how to collect this sort of data.

As the audit progresses it may become clear that some questions or inquiry foci are not relevant or useful to pursue and that other important foci arise from early conversations and responses to data gathering activities. Moreover, early responses to questionnaires may demonstrate the need for follow-up interviews, or vice versa. As these matters arise, alterations in the overall plan should be made in order to get the best possible data. While this may require some compromises with traditional research priorities on replicability and reliability, it should pay off with greater validity and relevance.

6. Prepare the information for analysis. The raw data gathered in surveys or interviews must be organized in ways that permit systematic analysis and not simply anecdotal accounts selected from large masses of data. Quantitative data gathered via surveys or statistical records generally must be coded (reduced to numerical constants) and entered into a computerized system for machine analysis. Qualitative data gathered from individual or group interviews, or from meeting minutes or observations, generally must be transcribed (if recorded on audio tape) and prepared for either hand analysis or analysis via a software system designed to thematize qualitative material. Technical assistance in analysis generally is available on most campuses, and audit committees should be encouraged to make use of these resources.

7. Analyze the data. A variety of formats are available, depending upon the type of data gathered and the degree of analytic sophistication desired. For instance, in some cases, univariate or marginal analyses of quantitative data will be adequate, and in other cases multivariate and/or regression analyses will be most useful and convincing to audiences. With regard to qualitative data, there also are numerous options, including tabulation of the number of times various themes or issues arise in various interviews, and the presentation of direct excerpted quotes of people's experiences and comments ("stories"). Sometimes personal quotes or narrative material (presented anony- 
mously) will be more convincing than a vast array of numbers, and sometimes the reverse will be true, depending upon the nature of the data, the audience, and the audit's overall purposes.

It usually is useful to present data in some comparative format, comparing and contrasting the views or experiences of one group of people with another or others (students vs. faculty, white students vs. Latina students vs. African-American students, men vs. women, faculty vs. staff, etc.). These comparisons help document and perhaps explain how people see and experience the school environment differently, as well as highlight important commonalities. For instance, reports from both the University of California at Berkeley (1991) and the University of Michigan (1994) indicate ways in which almost all students agreed on certain aspects of their university's climate but also how students of different racial/ethnic backgrounds perceived and experienced some things quite differently. Several of the other collegiate reports cited throughout have compared data gathered from students with those from faculty or staff, or responses from students and faculty of color with those from white students and faculty (or have made comparisons among African-American, Latino/a, AsianAmerican, and Native American populations). The University of California system report (1987) deliberately compared data from faculty and administrators at California campuses with data from colleagues at peer institutions throughout the nation. The Appendix presents several examples of data from these collegiate self-reports and different formats for comparing information from people of different social backgrounds or identity groupings or status levels in the organization.

8. Prepare a preliminary report or reports. Once the data is analyzed, and a preliminary or draft report written, it generally is useful to "test" the audit team's interpretation of these data, and any recommendations flowing from them, with members of key constituencies (institutional leaders, informal leaders, representatives of traditionally oppressed groups, etc.). The purpose of preliminary sharing is severalfold: (1) to test varied interpretations with people who may have special expertise and who have not been heavily involved in the entire audit process; (2) to gain new ideas and perspectives the audit team may have overlooked; (3) to engage others in developing recom- 
mendations for new programs and activities that might improve classroom and organizational situations; and (4) to test the waters for the appropriateness and relevance (or feasibility) of varied recommendations. This step should precede full public disclosure and can help solicit leadership support and advocacy for public feedback meetings later.

Open discussions of issues of discrimination and multiculturalism often draw heated exchange, and sharing the preliminary report may expose previously hidden conflicts and resistance. For instance, one audit team that presented their report to their unit's senior leadership was told flatly that their report was unacceptable. Evidently the leadership group felt that too much of the text was critical and negative about the organization, and they felt attacked and defensive. The audit team members felt that they had acted and reported in good faith and were extremely distressed. They felt they were faced with difficult choices: to "gentle" their report in ways that contradicted their findings; to rework their report in ways that contextualized the data and provided some examples of positive as well as negative findings; to quit the process. They chose the second alternative, presented a revised report to their leadership team, and negotiated a series of seminars and workshops for the leadership team to meet with them (and an external consultant) to discuss the findings in depth. A number of other audit teams have first presented their findings to leadership groups and then together with these groups have crafted more public documents. Other teams have operated more independently of organizational leaders and have moved directly to public or semi-public presentations. To the extent these arrangements can be negotiated ahead of time, there will be fewer surprises for everyone at this late stage.

9. Prepare a public report and action plans (the beginning of a new phase). This final phase of the audit team's work involves providing feedback or public access to their report to the entire school and especially to informants who participated in the data collection process. It also should include (depending upon the team's original charge and mission) recommendations for change based upon the findings. In this case, it is useful to detail the connection between findings and any specific recommendations, indicating clearly the data base(s) from which any particular recommendation flows. 
This "final" step also should lead to the creation of a "change team," a unit that will undertake the planning and implementation of changes that are based (more or less directly) on the results of the audit and its recommendations. Some organizations have conducted such audits as a way of appeasing protesting groups and then have allowed them to "die on the shelf." Others, with the best of intentions, have not planned for a change process and have wasted considerable time between the conduct of the audit and the introduction of coherent change-planning and action. On the other hand, some institutions have constructed the audit team as an "audit and change" team from the beginning, and under these circumstances the transition (as well as the organization's commitment to change) has been facilitated. An effective change team should include some members of the audit team, the better to facilitate the transition from data gathering to action, as well as members of the school's leadership cadre and representatives from varied stakeholder groups. In addition, recommendations can be fed into ongoing organizational units or programs invested with campus improvements, such as faculty development seminars, stratetegic planning operations, departmental reviews, etc. This step in the process takes us back to our discussion of the place of the audit in the organization's overall strategic plan and its plans for multicultural organizational change.

\section{A Few Caveats and Questions}

In the event an internal team is created to conduct the audit, members of this team must feel fully competent and responsible to carry out this effort. Regardless of the participation of external consultants, in the end nothing can substitute for such local legitimation of the process and empowerment of the people involved. Thus, by addressing the following questions early the team will be more likely to achieve its goals.

1. How much of the expertise required to accomplish these tasks lies within the university or college and its "team" and/or its support staff? How much external consultant assistance is needed, on which tasks? Which tasks will have to be contracted to other groups or to external parties? If an external agency conducts the 
audit, who "owns" the data and the process? How can internal capacity and empowerment best be promoted in this approach?

2. How can the institution's faculty development personnel and office(s) play useful roles in the audit and the parallel or subsequent change process? If these personnel have been involved in multicultural work previously, how can they connect their expertise and experience? If they have not had such prior preparation, how can they become better trained regarding multicultural issues and change processes? If, as often has been the case, faculty development work has focused primarily on classroom content/process how can personnel be educated and prepared for expanded roles dealing with the organizational climate issues that surround and influence the classroom?

3. How much time and energy will an internal team have available for this audit? How long will it take, and can a reasonable time-line be established at the outset? Will people's other functions be reduced or will this effort be carried as an overload (or will members receive additional compensation)? For instance, will team members be able to meet for a 2-hour period, perhaps once every 2 weeks, and still have time to do some preparatory reading and thinking and working between sessions? Will they be able to meet occasionally in longer, retreat sessions, early on and especially during the design and report preparation phases?

4. Since the design and conduct of a multicultural audit necessarily involve broader organizational politics (and accompanying power plays), how will team members be buffered and protected from formal or informal dissatisfaction, resistance, or even retaliation? Who will the audit team report to, when and how? What (if any) oversight will be exercised by this reporting office? What about peers' responses to team members?

5. If the effort to create a more multicultural organization requires reducing race and gender privilege, and if the data from the multicultural audit reveals evidence of such privilege and its effects, will the organization tolerate such exposure? Will privileged elites within the organization tolerate such exposure? Will such data and findings be heard and acted upon or defensively ignored and rejected? 
6. Most importantly, will the school's leadership cadre mobilize the resources (financial, political, emotional) necessary to follow up the audit and instigate, advocate, and support recommended changes? Will they have the vision, will, and skill to do so-or how can they be "encouraged" to do so?

The audit team, and its sponsors, may not be able to answer fully all these questions, but they should be addressed and readdressed at various times throughout the audit process. Unless teams are realistic and strategic in dealing with these issues, and many of the other questions and choices involved, they stand the risk of producing data that will not aid the multicultural change process or of not even engaging a true change process. Multicultural audits can be time consuming and difficult, but, when conducted effectively, they are an important tactic in the multicultural change process.

\section{References}

Brown, D., \& Tandon, R. (1983). Ideology and political economy in inquiry: Action research and participatory action research. Journal of Applied Behavioral Science, 19(3), 277-294.

Chesler, M. (1994). Strategies for multicultural organizational development. The Diversity Factor, 2(2), 12-18.

Chesler, M., \& Crowfoot, J. (1997, June). Racism in higher education II: Challenging racism and promoting multiculturalism in higher education organizations. Ann Arbor, MI: University of Michigan. C.R.S.O. Working paper \# 558.

Cox, T. (1980). Cultural diversity in organizations. San Francisco: Berrett-Koehler.

Deadham, S. (1980). Learning to select a needs assessment strategy. Training and Development Journal, 34(1), 56-61.

Gaventa, J. (1993). The powerful, the powerless and the experts: Knowledge struggles in an information age. In Park, Brydon-Miller, Hall \& Jackson (Eds.), Voices of change: Participatory research in the United States and Canada. Westport, CT: Bergin \& Garvey.

Green, M. (Ed.). (1989). Minorities on campus. Washington, DC: American Council on Education.

Jackson, B., \& Hardiman, R. (1994). Multicultural organizational development. In Cross, Katz, Miller, \& Seashore (Eds.), The promise of diversity. New York: Irwin.

Levitan, T., \& Wolf, L. (1994). Assessing diversity on campus: A resource guide. New Directions for Institutional Research, 81, 87-100. 
Lockwood, D., \& Luthans, F. (1980). Multiple measures to assess the impact of organizational development interventions. In J. Pfeiffer \& J. Jones (Eds.), The 1980 annual handbook for group facilitators (pp. 233-246). San Diego: Pfeiffer \& Co.

Miller, F. (1988). Moving a team to multiculturalism. NTL Handbook. Rosslyn,VA: Institute for Applied Behavioral Sciences.

Peters, M., \& Robinson, V. (1984). The origins and status of action-research. Journal of Applied Behavioral Science, 20(2), 113-124.

Smith, D. (1989). The challenge of diversity. Washington, DC: ASHE-ERIC Higher Education Report \# 5. (ERIC Document Reproduction Service No. ED314 987)

Stoecker, R., \& Bonacich, E. (1992). Why participatory research? The American Sociologist, 23(4), 5-14.

Thomas, J. (1984). Needs assessment: Avoiding the "hammer" approach. In J. Pfeiffer \& L. Goldstein (Eds.), The 1984 annual: Developing human resources (pp. 195-206). San Diego: University Associates.

Wunsch, M., \& Chattergy, V. (1991). Managing diversity through faculty development. To Improve the Academy, 10, 141-150.

\section{Organizational Self-Studies Cited}

Chesler, M., Wilson, M., \& Malani, A. (1993). Perceptions of faculty behavior by students of color. The Michigan Journal of Political Science, 16, 54-79.

George Mason University. (1991). Cross-cultural conflict and consensus building opportunities in the George Mason community. Fairfax, VA: The Conflict Clinic.

Indiana University. (1992). The Hoosier plan for minority enhancement. Bloomington, IN: (DRAFT)

LeMoyne College. (1991). Self-Study. Syracuse, NY.

Massachusetts Institute of Technology. (1986). The racial climate on the MIT campus. Cambridge, MA: Minority Student Issues Group.

Michigan State University. (1991). College level planning program: Faculty and academic staff diversity survey. East Lansing, MI: Social Science Research Bureau.

Pennsylvania State University. (1992). Enhancing diversity: Toward a better campus climate. State College, PA: Committee on Lesbian and Gay Concerns.

Princeton University. (1993). Race relations at Princeton. Princeton, NJ: (R. Simmons).

State University of New York. Campus climate and bias-related behavior. Albany, NY: Office of Student Affairs and Academic Programs.

University of California. (1987). The University of California in the 21st century: Successful approaches to faculty diversity. Los Angeles, CA: (J. Justus, S. Freitag, L. Parker).

University of California at Berkeley. (1991). The diversity project. Berkeley, CA: Institute for the Study of Social Change.

University of Michigan. (1992). Faculty, staff and students of color: A statistical profile for academic years 1981-82 through 1991-92. Ann Arbor, MI: Office of Affirmative Action and Office of Minority Affairs. 
University of Michigan. (1994). The Michigan study project: Executive summary. Ann Arbor, MI: Office of Academic Multicultural Initiatives.

University of Michigan School of Dentistry. (1995). Multicultural audit. Ann Arbor, MI: Multicultural Initiatives Committee.

University of Michigan School of Public Health. (1990). A report of student concerns about issues of race and racism in the school of public health. Ann Arbor, MI: Task Force on Racial and Cultural Concerns.

University of Wisconsin - Madison. (1987). Final report. Madison, WI: Steering Committee on Minority Affairs.

Wellesley College. (1989). Report of the task force on racism. Wellesley, MA: Task Force on Racism. (DRAFT)

Contact:

Mark A. Chesler

Professor of Sociology

University of Michigan

4028 LSA Building

500 S. State Street

Ann Arbor, MI 48109

Mark Chesler is the author of several research studies on race and gender discrimination and equity in organizations, with a special focus on higher educational settings. He also is active as a consultant in multicultural organizational change processes and a trainer of faculty and change agents concerned with issues of social justice. He is the 1998 recipient of the Emest Lynton Award for Faculty Professional Service \& Outreach, from AAHE. 


\section{Appendix}

Survey/questionnaire instruments

... and some illustrative results

Interview (individual and group) instruments

...and some illustrative results

Records retrieval formats

...and some illustrative results

\section{Survey/Questionnaire Instruments}

1. This first set of questions is from the Michigan State University report and focuses on general acceptance of and support for diversity. It uses a five-point Likert scale for response: $5=$ strongly agree, $4=$ agree, $3=$ neither agree nor disagree, $2=$ disagree, $1=$ strongly disagree.

- The Dean of my college is strongly committed to increasing the gender diversity of the faculty.

- The chair/director of my unit is strongly committed to increasing the gender diversity of the faculty.

- The chair of my department/school appreciates time I spend fostering multicultural understanding and cooperation.

- Recognition of differences in sexual orientation should be included in all University documents concerning diversity on campus.

- Issues of diversity and pluralism are often topics of discussion in my department/unit meetings.

- The University has done a good job of making the campus accessible to handicappers.

As this report indicates (p. 14), When presented with the statement: "my department has not made a good faith effort to recruit qualified minority faculty," $68.9 \%$ of the respondents disagreed. Similarly, 
when asked this same question relative to women, $69.6 \%$ disagreed. While the majority clearly believe that good faith effort had been made to recruit minority and women to faculty and academic staff positions, nevertheless $15.3 \%$ believed their departments had not made such efforts to recruit minorities and $13.3 \%$ believed their departments had not made such efforts to recruit women. As one might expect, more minority respondents believe that there has not been a good faith effort to recruit qualified minority faculty; however, $4.8 \%$ of non-minority men and $31 \%$ of non-minority women believe their department has not made a good faith effort to recruit qualified minority faculty. By race we find that $62.8 \%$ of the African-American respondents and $47.1 \%$ of the Hispanic respondents believe that there has been a lack of good faith effort to recruit qualified minority faculty while only $33.9 \%$ of Asian/Pacific Islanders and $25.8 \%$ of the Caucasian respondents agreed with this assessment.

2. This set of questions comes from the student survey conducted at Pennsylvania State University. It uses a five-point Likert scale to ask informants "How likely are you to respond in the following ways?": $5=$ very unlikely, $4=$ unlikely, $3=$ not sure, $2=$ likely, $1=$ =very likely.

- Tell a derogatory gay, lesbian, or bisexual joke.

- Tell someone I disapprove of anti-gay, anti-lesbian, or anti-bisexual remarks.

- Avoid taking a particular class because I heard the instructor was a gay man.

3. The following table comes from the Princeton report (p.16) in which students were asked to rate their degree of integration into varied aspects of life in the university community: 1=poor, 2=satisfactory, 3 =good, $4=$ very good, $5=$ outstanding.

Table 1 indicates that white students rated all three aspects of life at Princeton more positively than did students of color, with the largest (and perhaps the only substantial) differences occuring between white students and African-American or Latino students. 


\section{TABLE 1}

Classes of 1990, 1991, 1992 Graduation Survey Integration into University Community

\begin{tabular}{||c|c|c|c|c|c|c|c|}
\hline & White & Afr. Am. & $\begin{array}{c}\text { Afr. Am- } \\
\text { white } \\
\text { difference }\end{array}$ & Latino & $\begin{array}{c}\text { Latino- } \\
\text { white } \\
\text { difference }\end{array}$ & Asian & $\begin{array}{c}\text { Asian- } \\
\text { white } \\
\text { difference }\end{array}$ \\
\hline $\begin{array}{c}\text { Social } \\
\text { Life }\end{array}$ & 2.9 & 2.4 & -0.5 & 2.5 & -0.4 & 2.7 & -0.2 \\
\hline $\begin{array}{c}\text { Religious } \\
\text { Life }\end{array}$ & 2.9 & 2.6 & -0.3 & 2.9 & 0.0 & 2.7 & -0.2 \\
\hline $\begin{array}{c}\text { Cultural } \\
\text { Life }\end{array}$ & 3.0 & 2.4 & -0.6 & 2.6 & -0.4 & 2.8 & -0.2 \\
\hline
\end{tabular}

\section{Interview Instruments (Individual and Group)}

1. This first set of individual interview items comes from the report of Le Moyne College. Informants were asked to respond to the first question (a) in terms of a continuum ranging from $1=$ comfortable, through 2 to $3=$ generally $O K$ but some problems, through 4 to $5=$ uncomfortable, and to the later questions (b-e) using $1=y e s$ and $5=$ no as end points on a continuum.

a. In general, how would you characterize the racial atmosphere in the classroom at Le Moyne?

b. Would you say that Le Moyne is a community that welcomes both women and men? (In what way?)

c. Would you say that Le Moyne is a community which supports both women and men? (In what way?)

d. Would you say that Le Moyne is a community that welcomes individuals from different racial and ethnic groups? (In what way?)

e. Would you say that Le Moyne is a community which supports individuals from different racial and ethnic groups? (In what way?)

The use of a numerically anchored continuum permits a quantitative analysis of these interviews. As the report indicates (p. 55), "The 
key distinction is that between expressing a welcome to, say, women, persons of varying religious faiths, different social and cultural backgrounds, and abilities; and providing the support that such persons need to be happy and excel at Le Moyne. Table 2 reports respondents' impressions of the College's 'welcome' and 'support' for diversity in general and for various types of diversity. Respondents generally believed the College to be more successful in welcoming diversity than in supporting it."

\begin{tabular}{|l|c|c|l|c|c||}
\hline \multicolumn{7}{|c|}{ TABLE 2 } \\
\multicolumn{7}{|c|}{ Descriptive Statistics } \\
\hline \multicolumn{1}{|c|}{ WELCOME } & N & MEAN & \multicolumn{1}{|c|}{ SUPPORT } & N & MEAN \\
\hline Diversity & 54 & 2.33 & Diversity & 54 & 3.00 \\
\hline Sex & 60 & 1.20 & Sex & 57 & 1.98 \\
\hline Race & 56 & 1.86 & Race & 52 & 2.92 \\
\hline Ethnic & 54 & 1.96 & Ethnic & 51 & 3.12 \\
\hline Social Class & 54 & 2.19 & Social Class & 49 & 2.63 \\
\hline Age & 55 & 1.44 & Age & 51 & 1.78 \\
\hline Religion & 53 & 2.13 & Religion & 53 & 3.11 \\
\hline Ability & 50 & 2.12 & Ability & 44 & 2.82 \\
\hline Sexual Orientation & 48 & 4.42 & Sexual Orientation & 47 & 4.57 \\
\hline Residence Status & 43 & 1.65 & Residence Status & 40 & 2.90 \\
\hline
\end{tabular}

2. This second set of interview foci and questions, in this case for group interviews, comes from the report of the University of Michigan School of Public Health. The five questions that were used to focus discussion include:

- In thinking about your experiences here in the School of Public Health, list the 2 or 3 major barriers, problems, or concerns that have made you upset or angry, or that have had a negative effect on you.

- As you think of your interactions with faculty, what are things that professors do that are upsetting to you, or make you uncomfortable or angry in the classroom, or in more private interactions? 
- In thinking about your experiences as a graduate student, please describe any interactions with other students in the school that made you upset or angry.

- Thinking about the content of your courses, how is racism as it affects public health problems dealt with in your classes?

- Thinking about the issues we've talked about, list suggestions or recommendations that you would make to improve the school.

The report indicates that (pp. 5-6), "The nine most prominent themes that emerged from the interviews are:

1. There are Demands on Blacks to Educate Whites to Issues of Race and Racism.

2. Low Socio-Economic Status is Equated With Minority Status.

3. Issues of Race and Racism are Ignored in Course Content.

4. Faculty Devalue Students' Experiences and Options.

5. Faculty are Uninterested and Not Helpful in Advising and Counseling Students.

6. The Grading System is Subjective and Standards are Ambiguous.

7. There is a Lack of Tolerance for Different Political and Racial Perspectives.

8. The Lack of On-going Formal or Informal Dialogue Between Minority and Non-minority Students Limits Cross-Racial Understanding.

9. Experiences of Social Exclusion and Isolation Occur Between Minority and Majority Students.

A few examples of some of the things students said that were presented in the report may help make these points concrete:

"And then I have a class where the white students say that 6 out of 8 black students sat together in a class every day. And the white students told me that they viewed it as hostile. 'Well, why would you consider black students sitting together as hostile?' And she said, 'Well, they are separating themselves. 'Well, all the white students sit together. Is that hostile?' 'Well, no.' Then why is it hostile when black students sit together?" (p. 37) 
"They automatically assume, when they are teaching, I found in my first class, first semester, here that everything was low income, everything 'SES low,' is automatically black. There are a lot of white people who are low income but they do not stress that, they always stress that it is Black, so that gives everyone in the class the impression that everybody who is low income is black." (p. 12)

"Blacks get sick and tired of being the one who always have to teach white people about things, because black people learn about white people in school. How come white people can't learn about black people in school?" (p. 31)

'Whenever an issue concerning race came up, one of us was chosen, they directed the question, like, 'What do you think.' Well, you don't know where I grew up, maybe I grew up in an all white neighborhood, maybe I just don't identify with the Black culture. They don't know, they just assume because of the color of my skin that I am an authority. You are always selected-not to say that if you have something to contribute that that shouldn't happen, but to blatantly point you out and point the finger at you, instead of going around the classroom. That makes a big difference in terms of how you respond, too, because you are put on the defensive. 'Oh, they're choosing me because I am Black' instead of 'They are selecting me because I am a member of this class and I have something relevant to say.' It is a whole different perspective." (p. 9)

3. The next series of excerpts of students' voices come from the focus groups analyzed in the report from the University of California at Berkeley. These excerpts focus on issues of ethnic identity and prejudice or racism, first from a Chicano/Latino student and then from white students.

"They (African American students) talk about racism and then a Chicano/Latino will go, 'Oh yea, I know what you mean,' and they'll jusi look at you, or you know, or if you're not dark enough they don't think you've experienced it and I've come out and say, 'Well, Chicanos/Latinos face racism, too.' But, also, I always have to remind them: maybe you have a color barrier, but a lot of Chicanos/Latinos have a language barrier. A lot of times, Chicanos/Latinos they have a language barrier and it's always there." (p. 35)

'Many whites don't feel like they have an ethnic identity at all, and I pretty much feel that way too. It's not something that bothers me tremendously, but I think that maybe I could be missing something that other people have, that I am not experiencing." (p. 37) 
'I find myself embarrassed that I' $m$ white a lot of times (in small, highly diverse classes) I feel like I don't know anything because I am white. They say 'how do you know how we feel? How could you ever know?' Even though I try, I really want to be aware. I just feel like there is this big barrier stopping me." (p. 37)

'Everyone kind of has prejudices and biases what you don't really admit or you're not really conscious of, so you have to keep looking at what you're thinking and how you are judging Much as you can say 'I'm not racist, I don't have any preconceived ideas' you do, there's no way around it. So I think that it takes any experience like living with someone and working with someone, and each step you break down your own beliefs." (p. 38)

And finally from this report, a comment about the faculty.

"It's not that they're prejudiced or racist but it's just that they don't know. They're not sensitive on issues." (p. 35)

\section{Records Retrieval Formats}

1. A number of audits have included questions that can be addressed via the examination of organizational policies, procedures, and programs. For instance,

a. A request for each college or unit to share their plans for increasing minority enrollment and hiring would provide evidence of whether such planning has been done and whether it has been done systematically. Further requests may clarify whether such planning, if done, has led to the unit's own desired outcomes.

b. Colleges and units may be asked to identify the key personnel who are responsible for dealing, proactively and reactively, with issues related to diversity and multiculturalism. The existence of such named individuals may be taken as important evidence of organizational priorities, and these individuals also may be key informants for other questions.

c. College or unit policies and programs can be examined to determine if they provide mechanisms to deal with complaints or grievances with regard to issues of diversity and multiculturalism. If such mechanisms (ombudspersons, sexual and racial harassment policies, dispute settlement systems, infor- 
mal or formal grievance procedures) do exist, are they widely publicized and known throughout the unit?

d. The formal and informal curricula of a college or department may be examined (with experts from those units participating) to determine the degree to which courses are inclusive in content and procedures.

2. What follows are two rather self-explanatory tables: the first comes from the report by Indiana University and the second from the report by the University of California-where the U.C. data compared with data from several other "selected institutions."

\section{FIGURE 2: Minority Enrollment: Black vs. Hispanic Bloomington Campus, 1980-1991}

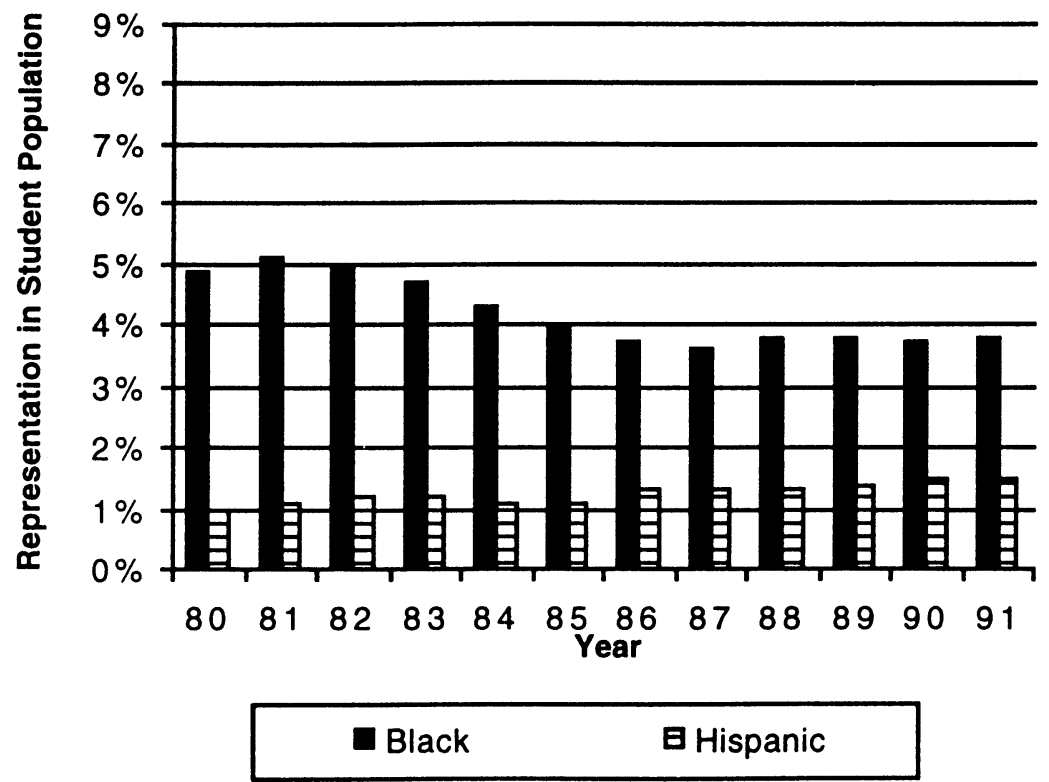

The number of Hispanic students in the Indiana University, Bloomington, campus population increased minimally in the 1980s. In contrast, black student representation decreased throughout the decade. 
FIGURE 3: Percent Minority Tenured and Non-Tenured On-Track Faculty

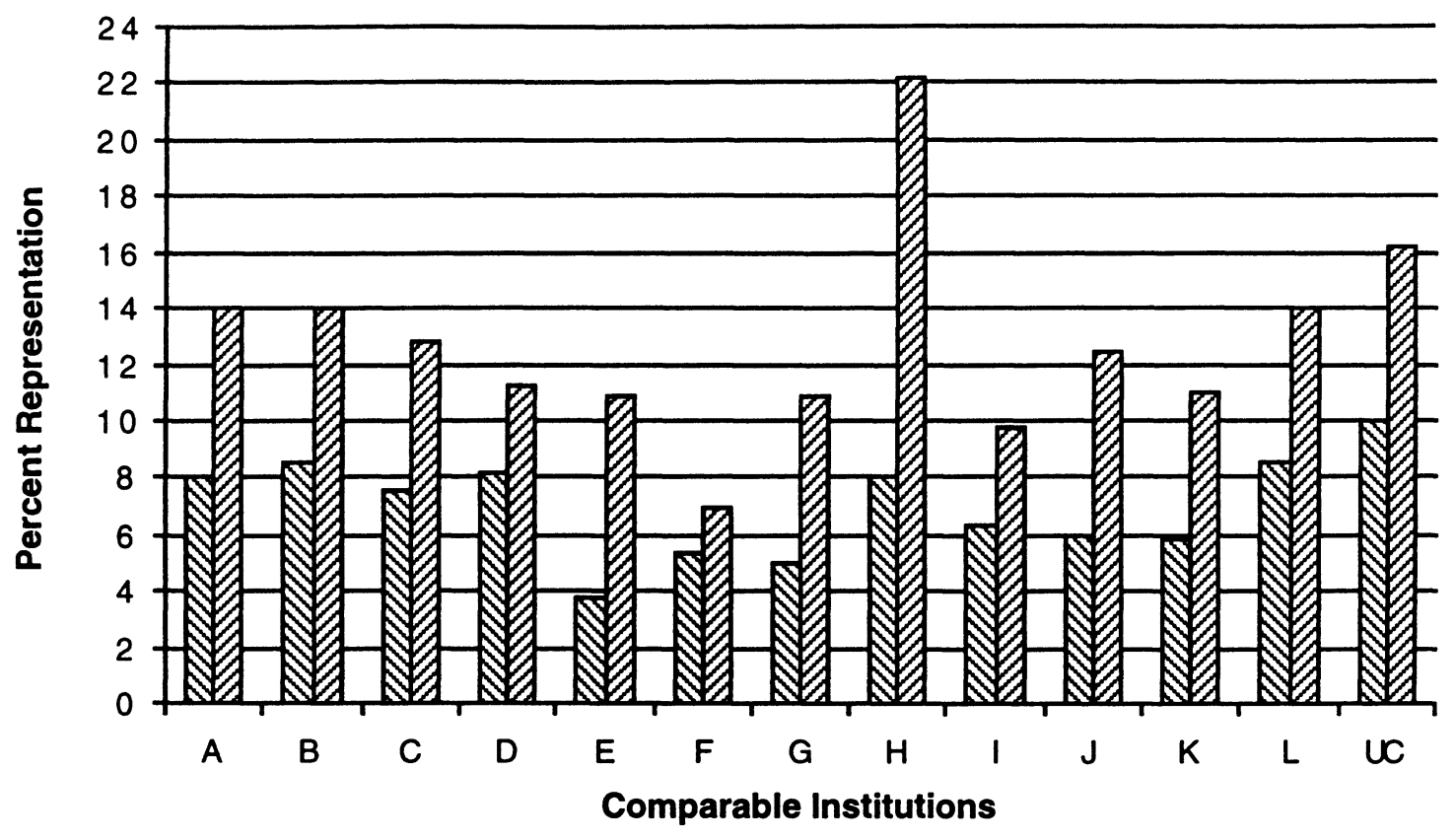

